\title{
LATIN AMERICAN SOCIETY FOR PAEDIATRIC RESEARCH (LASPR) SELECTED ABSTRACTS FROM THE XLVII ANNUAL MEETING
}

\author{
Asunción, Paraguay \\ October 18-21st, 2009 \\ Marta Sanabria (Paraguay), President \\ Roberto Fernandes da Costa (Brasil), President Elect \\ Roberto Shimabuku (Peru), General Secretary
}

1

RESPIRATORY DISTRESS SYNDROME ASSOCIATED WITH MECONIUMSTAINED AMNIOTIC FLUID IN TERM AND POST-TERM NEWBORNS: INCIDENCE, RISK FACTORS, MORBIDITY, AND MORTALITY

Meritano J, Abraham S, Di Pietro S, Gerez G, Fernández V. Hospital Materno Infantil "Ramón Sarda". Hospital "Pedro de Elizalde". Argentina

Introduction: Meconium-stained amniotic fluid (MSAF) is found in 5 to $30 \%$ of term and post-tern deliveries, 2 to $10 \%$ of them develop meconium aspiration syndrome (MAS). Mortality is between $4 \%$ and $40 \%$. Risk factors include greater MSAF density, altered fetal heart rate, deficient prenata monitoring, male gender, Apgar score less than 7, and oligoamnios. Objectives: To determine the incidence of MSAF and MAS in term and post-term newborns, to compare the incidence of respiratory distress syndrome (RDS) in those infants born with or without MSAF, and describe the risk factors distress syndrome (RDS) in those infants born with or without MSAF, and describe the risk factors
associated with MAS. Methods: Study design: retrospective cohort. Result variables: RDS and MAS. Predictive variables: MSAF. Inclusion criteria: newborn infants with 37 or more week's gestational age (GA) at delivery. Exclusion criteria: Less than 37 weeks GA, diabetic or hypertensive mothers, congenital malformations, or birth weight below the 10th percentile for GA. Case patients were those born with MSAF and control infants with clear amniotic fluid. Results: Of 10,332 deliveries recorded during the study period, 1150 had MSAF $(11.1 \%)$. There was positive association between MSAF and GA. The same was observed with MAS, the incidence of MAS was 3.9\% vs. $1.3 \%$ of RDS in control patients (RR 2.5, 95\% CI 1.3-3.7). MAS infants had more severe RDS, more pulmonary air leaks, lower Apgar score at 5 minutes, and higher mortality rate. Analyzing the RDS subgroup of infants we found less antenatal control, lower Apgar score at 5 minutes, majority of male gender and higher morbidity and mortality in the MSAF patients. Conclusions: This study shows that MSAF continues being a risk factor for RDS (with higher morbidity-mortality rates) in newborn infants at term or post-term pregnancies. Although there is a tendency toward lower incidence of advanced GA deliveries, there should be a higher proportion of well-monitored pregnancies and close observation of those mothers and infants with MSAF.

\section{2}

SELECTION OF STRAINS OF LACTOBACILLI AND BIFIDOBACTERIA WITH PROBIOTIC POTENTIAL

Figueroa G, Gotteland M, Troncoso M, Vega N, Astudillo F, Rivas P, Gómez M, Speisky H. Universidad de Chile.

Introduction: The selection of probiotic strains of Lactobacillus and Bifidobacterium is of growing interest for the development of functional foods. The aim of this study was to identify and select local strains of Lactobacillus and/or Bifidobacterium of human origin with probiotic potential. Methods: We analyzed 236 samples of milk and 526 stool samples from Chilean infants in Eugon agar and MRS agar for isolation of Lactobacillus and Bifidobacterium, respectively. The strains were identified by Gram stain and biochemical tests and the potential probiotic survival based on resistance to gastric $\mathrm{pH}$ (artificial gastric juice $\mathrm{pH}=2$ ) and resistance to $0.4 \%$ bile salts. Strains tolerant to both parameters were assessed for their antioxidant activity (by ORAC) and adherence to intestinal cells (Caco2). Lactobacillus was also assessed for their ability to inhibit two strains of $\mathrm{H}$. pylori, while Bifidobacterium against 4 foodborne pathogens: E. coli O157: H7, Salmonella enteric, Listeria monocytogenes and Campylobacter jejuni. Results: A total of 366 Lactobacillus and 82 Bifidobacterium strains were isolated. Among the Lactobacillus, 89/366 (24\%) were resistant to both $\mathrm{pH}$ and bile salts, while only $2 / 82(2 \%)$ of Bifidobacterium showed this ability. In 7/89 (8\%) Lactobacillus strains showed a higher antioxidant activity than control probiotic strains $(4.31 \pm 1.95 \mu \mathrm{m}$ Trolox equivalent/L). Bifidobacterium strains, in contrast, showed low activity. High adhesion rate to Caco2 cells $(>500$ bacteria $X$ 1000 cells) was found in $11 \%(9 / 82)$ of Lactobacillus strains. Some Lactobacillus strains showed antibacterial activity against $\mathrm{H}$. pylori, $9 / 89(10 \%)$ inhibited one of the 2 target strains and 7 inhibited both strains. Antagonistic effects against enteric pathogens were seen in 4/82 (5\%) of Bifidobacterium strains. Conclusions: Our laboratory now has various Lactobacillus and Bifidobacterium strains with probiotic potential to complete further studies.

Support: 07CN13PZT CORFO-INNOVA-13

\section{3}

MEASUREMENT OF INTIMA-MEDIA THICKNESS IN HEALTHY CHILDREN Espinoza A, Bagés C, Castillo-Durán C. Le Roy C. Departamento de Pediatría, Facultad de Medicina Campus Centro, Universidad de Chile. Clínica Alemana de Santiago. INTA, Universidad de Chile. Introduction: Arterial vascular endothelium injury is associated with metabolic syndrome, and ultrasound measurements of intima-media thickness (IMT) are available for adults, but normal values for children are unknown. Objective: To describe variations of arterial intima-media thickness in healthy Chilean children. Subjects and Methods: Healthy children between 5 and 15 years, with BMI between $\mathrm{p} 10-\mathrm{p} 85$, and no known chronic disease, and from upper-middle socioeconomic status wer recruited. Subjects were grouped by age. A Phillips iU22 ultrasound system with a $12-5 \mathrm{MHz}$ lineal transducer was used for measurements. Three measurements were performed on each subject, at the right common carotid artery (middle third) for maximal intima-media thickness. Automated IMT measurements were obtained with a specific program included in QLAB advanced quantification software. Weight, height, BMI, brachial perimeter and abdominal circumference were also measured. Results: Sixty-seven ( 36 males and 31 females) were recruited. Median IMT was $0.41 \mathrm{~mm}(0.40-0.56$ $\mathrm{mm}$ ); five children presented IMT above $0.50 \mathrm{~mm}$ and 13 others had measurements between 0.46 and $0.49 \mathrm{~mm}$. No significant differences in the IMT measurements according to age or gender were found The median IMT for those children with abdominal circumference $<50$ th percentile was the same as that for those $>50$ th percentile $(0.41 \mathrm{~mm})$. Conclusions: Advanced ultrasound equipment has the sensibility to measure IMT above $0.40 \mathrm{~mm}$. The measurements of maximal carotid intima-media thickness for apparently healthy Chilean children were within statistically normal ranges, except for a small group that presented potential risk of increased arterial thickness and required metabolic assessment.

EVIDENCE THAT CALCIUM DOES NOT AFFECT NONHEME IRON ABSORPTION

Gaitán D, Miranda C, Flores S, Olivares M, Pizarro F. Instituto de Nutrición y Tecnología de los Alimentos. INTA. Universidad de Chile.

Introduction: Since the 1980s, it has been accepted that calcium $(\mathrm{Ca})$ inhibits non-heme iron $(\mathrm{Fe})$ absorption in humans. However, some recent epidemiological studies find no effect for dietary $\mathrm{Ca}$ on the presence of $\mathrm{Fe}$. Objective: To clarify the effect of $\mathrm{Ca}$ on non-heme $\mathrm{Fe}$ absorption in humans, using doses from $0 \mathrm{mg}$ to $800 \mathrm{mg}$ of $\mathrm{CaCl} 2$. Methods: 15 healthy women participated in a non-heme $\mathrm{Fe}$ absorption study. The participants ingested solutions composed of $5 \mathrm{mg}$ elemental $\mathrm{Fe}$ (FeSO4) and 0 $\mathrm{mg}, 200 \mathrm{mg}, 400 \mathrm{mg}$ or $800 \mathrm{mg}$ of $\mathrm{Ca}(\mathrm{CaCl} 2)$. Each dose was labeled as $2 \mu \mathrm{Ci} \mathrm{de}{ }^{55} \mathrm{Fe}$ or $0.7 \mu \mathrm{Ci}{ }^{59} \mathrm{Fe}$ Results: Geometric averages and \pm 1DS ranges for Non-heme Fe absorption for $0 \mathrm{mg}, 200 \mathrm{mg}, 400$ $\mathrm{mg}$ or $800 \mathrm{mg}$ doses were, respectively, $17.9 \%$ (7.0-45.6); 15.9\% (7.6-33.6); $15.3 \%(5.8-40.2)$; and $11.9 \%(4.7-30.5)$. Repeated measures Anova $p=0.086 ; F=2.36$. Discussion: Our results differ from previous studies in that it $\mathrm{Ca}$ does not inhibit absorption of non-heme $\mathrm{Fe}$ when administered together in the form of $\mathrm{CaC} 12$ at doses of $800 \mathrm{mg}$ or less. The differences might be explained by the form in which $\mathrm{Ca}$ and non-heme Fe were administered, which in earlier studies did not allow isolation of the effect of Ca from that of other dietary components. In a normal serving, Ca usually does not exceed $800 \mathrm{mg}$; thus it would not have an inhibitory effect on non-heme Fe absorption. This fact explains the results from recent epidemiological studies. Conclusion: $\mathrm{Ca}$ at doses equal to or lower than $800 \mathrm{mg}$ does not inhibit non-heme $\mathrm{Fe}$ absorption. 


\section{5}

COPPER SUPPLEMENTATION DOES NOT INHIBIT IRON ABSORPTION

Olivares M, Pizarro F, López de Romaña D, Ruz M. Laboratorio de Micronutrientes, Instituto de Nutrición y Tecnología de los Alimentos (INTA), Universidad de Chile. Departamento de Nutrición, Facultad de Medicina, Universidad de Chile.

Introduction: Combined supplementation with iron $(\mathrm{Fe})$ and copper $(\mathrm{Cu})$ is a strategy which can be used to improve the nutritional status of both micronutrients in a population. However, there is concern about the negative interactions between these two minerals. Objective: To measure the effect of acute $\mathrm{Cu}$ administration, given as an aqueous solution, on the absorption of Fe. Methods: Forty-three healthy adult subjects participated in $3 \mathrm{Fe}$ absorption studies. Subjects received $0.5 \mathrm{mg}$ of $\mathrm{Fe}$ (as ferrous sulfate) alone or with $\mathrm{Cu}$ (as copper sulfate) at $0.5: 1,1: 1$ or $2: 1 \mathrm{Cu}: \mathrm{Fe}$ molar ratios (study I, $\mathrm{n}=15$ ) or at $4: 1,6: 1$ or $8: 1 \mathrm{Cu}: \mathrm{Fe}$ molar ratios (study II, $\mathrm{n}=14$ ), as an aqueous solution on days 1 , 2,14 and 15 of the study. In study III subjects $(n=14)$ received $4 \mathrm{mg}$ of $\mathrm{Fe}$ alone or with $\mathrm{Cu}$ at $1: 1$ molar ratio on days 1 and 2 of the study. $\mathrm{Fe}$ and $\mathrm{Cu}$ were given as aqueous solutions. Fe absorption was assessed by erythrocyte incorporation of radioisotopes $55 \mathrm{Fe}$ and $59 \mathrm{Fe}$. Iron absorption results were expressed as geometric means and range of $1 \mathrm{SD}$. Results: Absorption of $0.5 \mathrm{mg} \mathrm{Fe}$ alone or at $0.5: 1,1: 1,2: 1 \mathrm{Cu}: \mathrm{Fe}$ molar ratios were $34.4 \%(17.3 \%-68.5 \%), 40.9 \%(24.9 \%-67.2 \%), 48.3 \%$ $(24.8 \%-94.1 \%)$ and $50.2 \%(25.3 \%-99.5 \%)$, respectively (repeated measures ANOVA, NS). Absorption of $0.5 \mathrm{mg} \mathrm{Fe}$ alone or at 4:1, 6:1, 8:1 Cu:Fe molar ratios were $28.7 \%(12.1 \%-67.9 \%), 21.5 \%$ $(6.5 \%-71.5 \%), 29.6 \%(10.3 \%-85.4 \%)$ and $36.5 \%(18.3 \%-73.1 \%)$, respectively (repeated measure ANOVA, NS). Absorption of $4 \mathrm{mg}$ Fe alone or at 1:1 Cu:Fe molar ratio were 20.8\% (6.8-63.9) and $14.9 \%(7.0-31,8)$ (paired Student $\mathrm{t}$ test, NS). Conclusion: Combined $\mathrm{Cu}$ and $\mathrm{Fe}$ administration, as an aqueous solution, at different doses and molar ratios does not inhibit Fe bioavailability. This information could help in the design of copper and iron supplementation programs. Our results support the hypothesis that DMT1 is not physiologically relevant for copper absorption in humans.

Supported by grant 1070665 from FONDECYT-Chile.

\section{8}

COMPARATIVE STUDY OF ACUTE BACTERIAL MENINGITIS (ABM) CAUSED BY SEROTYPES OF STREPTOCOCCUS PNEUMONIAE INCLUDED AND NOT INCLUDED IN THE PNEUMOCOCCAL CONJUGATE VACCINE (PCV7)

Aranda C, Sanabria G, Delgado V, Araya S, Lovera D, Arbo A. Instituto de Medicina Tropical. Universidad Nacional de Asunción. Asunción, Paraguay.

Objective: To compare the clinical progression of cases of ABM caused by serotypes included and not included in the PCV7 vaccine. Materials and Methods: A retrospective observational study performed in the Instituto de Medicina Tropical on patients (pts) under 16 years of age with ABM in whom $S$. pneumoniae were isolated in cerebrospinal fluid (CSF) and/or blood. Serotipification of the Streptococcus strains were done by Kellung method. Pts were grouped depending if the serotype isolated was included in the PCV7 or not, with comparison of demographic, clinical, and laboratorycharacteristics, as well as predisposing factors and neurological sequelae. Results: The study included 48 pts with a mean age of $4 \pm 6$ years and a similar distribution by sex. Seventeen cases $(47 \%)$ were caused by serotypes included in the PCV7. No differences between ABM cases caused by serotype found and not found in the vaccine were seen regarding to predisposing factors $(1 / 19 \mathrm{vs} 0 / 17)$, mean age ( $3.3 \pm 4.5$ vs $4.5 \pm 6.0$ years), previous antibiotic therapy ( $3 / 16 \mathrm{vs} 0 / 17)$, pre-admission duration of illness ( $2.0 \pm 1.7$ vs $2.6 \pm 2.4$ days), Glasgow scale $<12$ on admission ( $21 \%$ vs $29 \%$ ), and seizures ( $52 \%$ vs $47 \%)$. Resistance to penicillin appeared in only $5 \%$ of non-vaccine strains $(\mathrm{p}<0.01)$. Overall mortality for the series was $13 / 48(27 \%)$, without differences between groups. Severe sequelae were seen in $14 \%$ of non-vaccine cases and $29 \%$ of those with strains addressed by the vaccine $(p=0.32)$. Conclusion: No difference was seen in the clinical progression of cases of ABM caused by serotypes included or not in the PCV7 vaccine. The PCV7 vaccine might show more advantage in protection against serotypes with greater prevalence of penicillin resistance.

\section{6}

\section{TREATMENT OF PEDIATRIC PITYRIASIS ALBA PATIENTS WITH 0.03\%} TACROLIMUS OINTMEN'T

Buongermini A, Mena C, Valencia A. Hospital Infantil de México Federico Gómez. México.

Background: Pityriasis alba (PA) is a skin condition that is common in childhood but whose etiology is still unknown. It is one of the lesser criteria for diagnosis of atopic dermatitis (AD), which leads many authors to suggest that these patients should be treated as having AD. Many treatment have been tried, including steroids, with little response. Tacrolimus is a calcineurin inhibitor with anti-inflammatory properties similar to those of corticosteroids that is proven effective in $A D$, an which may therefore be a useful alternative for treating PA patients. Objectives: To evaluate the clinical response to tacrolimus ointment $0.03 \%$ of pediatric PA patients and correlate the presence of PA with DA. Methods: We performed a clinical study including 40 patients ages 2 to 18 years diagnosed with PA who presented for dermatology consultation at the Federico Gomez children' hospital in Mexico from March to July 2008. The subjects were divided into two groups, Group A, treated with tacrolimus $0.03 \%+$ sunscreen, and Group B, treated with sunscreen alone. Children were evaluated clinically in week 8 of treatment based on the number of lesions and their total area. Results: Of the 40 subjects, after treatment a greater reduction was seen in the number of lesions in the 21 subjects from the tacrolimus + sunscreen group compared to the group receiving only sunscreen $(\mathrm{p}=0.005)$; however, although both groups showed a reduction in total area, no statistically significan difference was found between groups. Conclusion: The use of topical tacrolimus ointment at $0.03 \%$ is a useful adjuvant to sunscreen in the treatment of PA. The adjunctive combination resulted more effective than use of sunscreen alone in diminishing the number of lesions, and equally effective in reducing their overall area.

\section{7}

EVALUATION OF A CLINICAL PREDICTION RULE FOR THE INITIAL MANAGEMENT OF CHILDREN WITH PNEUMONIA IN AN OUTPATIENT SETTING

Torres F, Ossorio MF, Cutri A, Leonardelli A, Chiolo MJ, Ferrero F. Hospital General de Niños Pedro de Elizalde. Argentina

Introduction: Despite more than half of pneumonias in children are due to viruses, initial treatmen usually includes antibiotics. In order to limit this tendency, a clinical rule to predict etiology in children hospitalized for pneumonia was developed (Bacterial Pneumonia Score -BPS-), but its performance has not yet been evaluated in outpatients. Objective: To evaluate the performance of a clinical prediction rule (BPS) for the initial management of children with pneumonia, in an outpatient setting. prediction rule (BPS) for the initial management of children with pneumonia, in an outpatient setting.
Methods: We included outpatients aged 3-60 months with mild pneumonia (according to WHO). BPS (range: -3 to 15 points) was calculated in all patients; only in those with BPS $\geq 4$ antibiotics were ndicated. Clinical outcome in both groups was evaluated at the second and seventh day. Poor outcome was defined as persistence of fever or tachypnea (or decrease in respiratory rate $<5$ breaths/minute from baseline) by the second day, or signs of severe pneumonia, hospitalization or use of antibiotics (or changing antibiotics) at any time. Association between clinical outcome and treatment (with or without antibiotic) was evaluated by chi square; significance level $\mathrm{p}<0.05$. Results: 108 patients aged $25.3 \pm 16.5$ months were included. The BPS ranged between -2 and 11 points; 48 patients with a score $\geq 4$ received antibiotics. Only 3 patients showed poor clinical outcome: 1 otitis (not receiving antibiotics), 1 gastroenteritis and 1 pleural effusion (both were receiving antibiotics). There were no differences in clinical outcome between groups (with and without antibiotics) at the second ( $\mathrm{p}=0.15$ OR: $2.73 ; 95 \%$ CI: $0.74-11.1)$ and at seventh day ( $p=0.5$; OR: $0.39 ; 95 \% \mathrm{CI}$ : 0.01-5.74). Conclusion: Using BPS was safe for initial management of children with community-acquired pneumonia in an outpatient setting. Using BPS allowed not using antibiotics in more than half of patients diagnosed with pneumonia.

\section{9}

EFFECTS OF PRENATAL MALNUTRITION ON THE EXPRESSION OF CORTICOTROPIN-RELEASING HORMONE, HYPOTHALAMIC BRAIN-DERIVED NEUROTROPHIC FACTOR, AND MARKERS OF KIDNEY DAMAGE

Ayala M, Núñez H, Pérez H. Universidad de Chile.

Introduction: Maternal undernutrition may program permanent physiological and biochemical changes in the fetus. Recent epidemiological studies suggest an association between low weight at birth and hypertension in adult life. Hypertension is both a cause and complication of chronic kidney disease (CKD). Objective: To determine mRNA expression of corticotropin-releasing hormone (CRH) and brain-derived neurotrophic factor (BDNF) in the hypothalamus, and kidney injury molecule 1 (KIM-1), heme oxygenase neurotrophic factor (BDNF) in the hypothalamus, and kidney injury molecule 1 (KIM-1), heme oxygenase
1 (HO-1) and secreted phosphoprotein 1 (Spp1) in kidney tissue, as well as plasma corticosterone levels and 1 (HO-1) and secreted phosphoprotein $1(\mathrm{Spp} 1)$ in kidney tissue, as well as plasma corticosterone levels and
systolic pressure at 1 and 60 days of postnatal life in rats subjected to prenatal undernutrition. Methods: Prenatal undernutrition of pups was induced by submitting pregnant rats to diet restriction of $10 \mathrm{~g}$ daily $(\mathrm{n}=8 /$ day $1 ; n=8 /$ day 60$)$. Pups born from dams with free access to the standard laboratory diet served a controls ( $\mathrm{n}=8 /$ day $1 ; n=8 /$ day 60$)$. At 1 and 60 days of postnatal life normal and undernourished animals were decapitated. Plasma corticosterone was measured using the corticosterone ELISA kit. Total RNA was isolated from the hypothalamic and kidney tissue and reverse transcribed. Total cDNA was amplified and quantified for real time PCR. Systolic and diastolic blood pressure were measured. Results were analyzed by unpaired two-tailed Student's t-test (SYSTAT v11). Results: At day 1 and day 60 of postnatal life undernourished rats showed lower body weight $(\mathrm{p}<0.01)$ and significantly higher plasma corticosterone than normal rats $(\mathrm{p}<0.01)$. At day $60 \mathrm{vs}$. day 1 of postnatal life undernourished rats showed significantly higher $\mathrm{CRH}$ mRNA expression $(\mathrm{p}<0.01)$ but no significant change in BDNF mRNA expression in hypothalamic tissue. Interestingly, they showed significantly higher KIM-1 and HO-1 mRNA expression in kidney tissue $(\mathrm{p}<0.01)$ and significantly increased systolic pressure, $(\mathrm{p}<0.01)$ compared to the normal rats, but without significant change in Spp-1 mRNA expression. Conclusions: The mRNA expression of CRH in hypothalamus, KIM-1 and HO-1 in kidney tissue and plasma levels of corticosterone as well systolic pressure at 60 day of postnatal life is increased in rats to experiment prenatal undernutrition. However, no significant change in the expression of BDNF in hypothalamus and Spp-1 in kidney tissue. The results suggest an event sequence that contributes to programming of hypertension and probably early renal injury or susceptibility to renal injury, as well as that prenatal undernutrition is a risk factor for development of renal failure in the adult life of the rat.

Fondecyt 1080684

\section{0}

PROBIOTICS IN THE MANAGEMENT OF ACUTE ROTAVIRUS DIARRHEA IN BOLIVIAN CHILDREN: A RANDOMIZED, DOUBLE-BLIND, CON TROLLED TRIAL OF TWO DIFFERENT PREPARATIONS

Grandi G, Medina M, Soria R, Teran C, Araya M. Centro Pediátrico Albina R. de Patiño - Bolivia Instituto de Nutrición y Tecnología de los Alimentos - Chile.

Objective: To compare the effect of two probiotic products in the treatment of acute diarrhea in children less than 2 years of age. Design: Randomized double-blind controlled clinical trial in children hospitalized for acute rotavirus diarrhea. Setting: Pediatric Center Albina Patiño. Participants: Children aged 1-23 months. Intervention: Children were randomly assigned to receive one of three treatments: oral hydration solution (control group); oral hydration solution plus Saccharomyces boulardii (GB group), or oral hydration solution plus a compound containing Lactobacillus acidophilus, Lactoba cillus rhamnosus, Bifidobacterium longum and Saccharomyces boulardii (GARLB group). Outcome measures: Primary outcome was duration of diarrhea. Secondary outcomes were duration of fever, vomiting, and hospitalization. Results: 64 of 70 cases completed the protocol. Baseline characteristics were similar in the three groups. Median duration of diarrhea was shorter $(p=0.04)$ in children who received S. Boulardii (58 hours) than in controls ( 84.5 hours). Median duration of fever was shorter ( $\mathrm{p}=0.0042)$ in children who received S. Boulardii (18 hours) than in controls (67 hours). Duration of vomiting was shorter in GARLB group ( 0 hours) than in controls ( 42.5 hours $)(p=0.041)$. There was no effect on duration of hospitalization $(\mathrm{p}=0.31)$. There were no differences between the two intervened groups. Conclusions: Both products decreased duration of diarrhea, but the difference wa significantly only for S. Boulardii. S. Boulardii decreased duration of fever and with the mixed product there was no vomiting. Results support the use of probiotics in the treatment of acute rotavirus diarrhea. The appropriate amounts of bacteria should be established for each probiotic when administered in mixtures to induce the best effect and at the same time are safe for the patient. Use of probiotics would be especially relevant in societies where diarrhea and malnutrition have high prevalence. 
11

HIGH ARTERIAL BLOOD PRESSURE IS ASSOCIATED WITH REDUCED NIGHTTIME SLEEP AMOUNT IN OBESE CHILDREN

Weisstaub $\mathbf{G}^{\mathbf{1}}$, Burrows $\mathrm{R}^{1}$, Santos $\mathrm{J}^{2}$, Peirano $\mathrm{P}^{\mathbf{1}}$. (1) Institute of Nutrition and Food Technology (INTA), University of Chile, and (2) Department of Nutrition, Diabetes and Metabolism, School of Medicine, Pontific Catholic University of Chile, Santiago, Chile. Email gweiss@inta.cl

Introduction: There is a growing trend among children and adolescents toward obesity and chronic diseases. Sleep patterns have also been tied to chronic conditions. Objective: To investigate whether high blood pressure is associated with nighttime sleep amount in obese children. Subjects and
Methods: Subjects were evaluated after signed informed consent was obtained from the parent(s) or guardian. Participants were assessed for their Tanner stage, blood pressure and BMI (z) score (CDC growth chart). High arterial pressure was diagnosed if systolic or diastolic pressures were $>90$ percentile. Nighttime sleep amount was determined from actigraphic data (Actiwatch, Mini Mitter Co, installed on the non-dominant wrist during 3 days) using an automated procedure. The association between variables was analyzed by means of the Mann-Whitney U test. Results: 143 children ranging 6 to 12 years old were recruited ( $45 \%$ girls). Differences in sleep amount were apparent between children with high and normal blood pressure, with high blood pressure children showing less sleep children with high arterial pressure sleep almost one hour less per night compared with normotensive children. We speculate that a reduced amount of nighttime sleep is a risk factor for systemic arterial hypertension in obese children.

Funded by DI of University of Chile: MULT $05 / 06-2$

\section{2}

\section{MEASUREMENT OF VISCERAL ADIPOSITY IN WELL-NOURISHED} SCHOOLCHILDREN AND ADOLESCENTS

Bagés MC; Espinoza A, Le Roy C, Castillo-Durán C. Instituto de Nutrición y Tecnología de los Alimentos (INTA), Universidad de Chile. Departamento de Pediatría, Facultad de Medicina Campus Centro, Universidad de Chile. Clínica Alemana de Santiago, Servicio de Radiología, Santiago, Chile.

Introduction: Increases in the visceral adipose are more closely associated with metabolic complications in obesity than are increases in the subcutaneous adipose tissue compartment. Early identification of at risk children would allow better focus of preventive measures. Objectives: To study the measurements of visceral adiposity in healthy schoolchildren and adolescents. Subjects and Methods: We evaluated 130 well-nourished Chilean schoolchildren and adolescents (BMI $\geq$ p10 and $\leq$ p85) of both sexes, ages 5-14 years, using anthropometric and imaging techniques (abdominal segment, and hepatic ecogenicity). Results: Measurement of visceral adiposity by abdominal ultradifferences in schoolchildren. The best correlations were found in males age 5-7 for both body mass index (BMI) and abdominal perimeter (AP), with ratios of visceral adiposity (VA) and sub-cutaneous adiposity (SCA) of $(r=-0.64$ and -0.60 , respectively), also found in girls ages $5-7(\mathrm{r}=-0.57$ and adiposity (SCA) of $(r=-0.64$ and -0.60 , respectively), also found in girls ages $5-7(r=-0.57$ and
-0.74 , respectively) and girls $10-11$ years $(r=-0.70$ and -0.60 , respectively). Conclusions: There were no gender differences in visceral adiposity measurements in schoolchildren, but there were differences in adolescents. The values obtained should be supplemented by further measures to establish normal parameters for visceral adiposity and distinguish them from the values found in obese children and adolescents. amount $(8.3$ vs. $9.2 \mathrm{hrs}, \mathrm{p}<0.001)$. Conclusions: These results, although preliminary, show that obese ultrasound: lumbar spine - rectus abdominus muscle segment, rectus abdominus muscle - skin sound in healthy children showed a normal distribution according to sex and age, without sex

\section{4}

RELATIONSHIP BETWEEN CHAOTIC HOME ENVIRONMENT AND OBESITY IN A SAMPLE OF CHILEAN YOUTH

Castillo M, Guendelman M, Rosas L, Delva J. Programa Fulbright. INTA, Universidad de Chile. Universidad de California, San Francisco.

Background: Obesity is a major contributor to the global burden of chronic disease and disability. In recent decades, Latin America has experienced a rapid rise in obesity, especially among children. Over 20\% of the Chilean school-age population is overweight or obese. Little is known about the relation between family disorganization and obesity among youth. Objective: We investigated whether a chaotic home environment was associated with overweight and obesity and diet-related behaviors in a sample of Chilean adolescents. Methods: The study subjects have been part, since they were 6 months olds, of a longitudinal follow up study in Santiago-Chile. For this study a cross-sectional sample of 118 teenagers (54 females; $M=14.4$ years; $S D=.6$ years) was interviewed about their dietary practices, physical activity, and demographic characteristics. Participants completed the 15-item Confusion, Hubbub, and Order Scale (CHAOS) scale, measuring the level of chronic chaos, confusion and disorder in their home environment. Sample questions include, "our home is a good place to relax", "we almost always seem to be rushed", and "we have a regular routine at home". Body mass index was classified using anthropometric measurements collected by a nurse. Logistic regression was used to investigate the association between CHAOS and child weight status. Results: $62 \%$ of participants were classified as normal weight, $17 \%$ were overweight and $20 \%$ were obese. Adolescents from chaotic home environments were more likely to be overweight [OR 2.75, 95\% CL 0.95-7.92] or obese [OR 3.53, 95\% CL 1.26-9.89] compared to adolescents from low CHAOS households ( $\mathrm{p}=$ .02). Additionally, participants from high CHAOS households were more likely to eat alone ( $p<.01$ ), eat between meals even when not hungry $(\mathrm{p}<.05)$, snack when nobody is watching $(\mathrm{p}<.01)$, and skip meals $(\mathrm{p}<$ .05). Participants from high CHAOS homes were more likely to be depressed $(\mathrm{p}<.05)$. Overweight and obese participants were more likely to skip meals compared to normal weight participants $(\mathrm{p}<.05)$. Per capita household income, pubertal stage, mother's BMI, age and gender were not associated with CHAOS score or BMI categories. Conclusion: A chaotic and disorganized home environment is associated with approximately a threefold risk for overweight and obesity and with important specific dietary practices among youth in ou sample. The findings suggest that before providing diet-related guidance to overweight and obese children, pediatricians may consider seeking information about the quality of their home environment.

Supported by Programa Fulbright y NIDA RO1 DAD21181

\section{5}

INTIMA-MEDIAL THICKNESS AND CAROTID ARTERY STIFFNESS IN OBESE ADOLESCENTS AND THEIR RELATION WITH METABOLIC SYNDROME

Balboa P, Torrejón C, Hevia M, Schilling W, Ureta E, Valenzuela X. Departamento de Pediatría y Cirugía Infantil Norte, Facultad de Medicina, Universidad de Chile. Servicio de Imagenología y Nutrición del Hospital Roberto del Rio. Chile.

Introduction: Obese adolescents are at increased cardiovascular risk associated with non-transmissible chronic diseases like type 2 diabetes mellitus, dyslipidemia and hypertension. Early assessments of vascular compromise include measuring intima-medial thickness (IMT) and carotid artery stiffness (CAS). Objective: Evaluate whether obese adolescents have greater vascular compromise as measured by IMT or CAS than non-obese adolescents, and whether this compromise is greater in those with metabolic syndrome. Material and Methods: We studied all obese children (BMI/age > p95) who consulted the nutrition clinic of the Roberto del Río Hospital between 31/10/2006 and 30/07/2009. Fasting serum concentrations of glucose, lipids, insulin and internal carotid artery ultrasound were measured. Oral glucose-tolerance test was performed on each obese patient, and before and 2-hour postload serum glucose and insulin levels were obtained. Controls were non-obese children (BMI/age $\mathrm{p} 10-85$ ) requiring blood tests for non-nutritional or non-endocrine disorders in the same hospital. We used parametric and nonparametric tests for statistical analysis. Results: 38 obese adolescents wer admitted ( 20 women), age $12.9 \pm 0.3$ years and 18 controls ( 14 female), age $13.8 \pm 1.2$ years. Eleve (29\%) had metabolic syndrome according to the Ferranti criteria. Values measured in IMT bulb and internal carotid artery were significantly higher in obese children compared with controls (IMT Bulb: $0.53 \pm 0.2 \mathrm{~mm}$ vs. $0.37 \pm 0.1 \mathrm{~mm}, \mathrm{p}<0.0001$; IMT internal carotid: $0.48 \pm 0.2 \mathrm{~mm}$ vs. $0.26 \pm 0.04$ $\mathrm{mm}, \mathrm{p}<0.0001)$. There was no difference in CAS values between obese children and controls $(4.13 \pm$ 1.7 vs. $3.87 \pm 1.25, \mathrm{p}>0.05$ respectively). No significant difference in IMT or CAS was observed between obese children with and without metabolic syndrome. Conclusion: IMT measured at the bulb and internal carotid artery is greater in obese adolescents, which indicates probable early vascular damage in this population.

Funded by Chilean Society of Pediatrics

\section{3}

CIRCULATING LEVELS OF ADVANCED GLYCOSYLATION END PRODUCTS DURING THE FIRST YEAR OF LIFE

Piccardo Van de Perre C, Mericq V, Cai W, Vlassara H, Uribarri J. Instituto de Investigación Materno Infantil, Universidad de Chile, Santiago, Chile. Department of Geriatrics, The Mount Sinai School of Medicine, New York, NY. Department of Medicine, The Mount Sinai School of Medicine, New York, NY. Chile.

Introduction: Advanced glycation end products (AGEs), a group of compounds with significant pro-oxidative and pro-inflammatory actions, may derive from food and contribute to several chronic diseases such as diabetes. Little is known about AGE levels early in life. Objective: To measure circulating AGE levels in children at birth, 6 and 12 months of life. Methods: Patients: Healthy mothers $(n=60)$ presenting for delivery and their infants were evaluated at birth and at 6 months and 12 months of life. A blood sample was obtained from the mothers and the umbilical cord of newborns at delivery and at 6 and 12 months for testing two distinct AGEs, N-carboxymethyl-lysine (CML) and methylglyoxal (MG) derivatives, 8-isoprostane, fasting glucose and insulin. Results: A positive correlation was found between maternal and newborn levels of CML $(r=0.734, p=0.001)$ and MC $(\mathrm{r}=0.593, \mathrm{p}=0.001)$. Newborn serum CML levels were $\sim 60 \%$ of maternal $(2.8+1$ versus $4.8+3$ $\mathrm{u} / \mathrm{ml}, \mathrm{p}=0.001$, respectively) and reached the maternal values at 12 months as feeding transitioned from breast milk to a combination of powdered milk, formula, and solid food intake. MG levels at birth were similar to the mothers' and increased significantly during the next 12 months. In contrast, levels of 8-isoprostane, high in the newborn, decreased progressively over the first year of life. Quartile AGEs analyses revealed a significant association between maternal MG and infant insulin level $(p=0.027)$. Conclusions: Serum AGE levels increase significantly in the first year of life in association with the introduction of foods rich in AGEs. These findings support dietary AGEs as contributors to the body pool of AGEs and possibly to disease risk.

\section{6}

\section{MATERNAL PERIODONTAL DISEASE AND RISK OF PRETERM BIRTH: A} CASE-CONTROL STUDY

Grandi C, Trungadi M, Meritano J. Maternidad Sardá. Argentina. systemic inflammatory responses that increase the risk of preterm birth in women of childbearing age. The goal of this study was to establish whether or not periodontal disease is a risk factor for preterm birth and to evaluate any association with gestational age. Material and Methods: This is case-control study in which fifty-three post partum women with singleton gestation who gave birth before the 37th week (cases) and seventy-nine term deliveries (controls) were compared. Clinical periodontal parameters on a full-mouth basis were determined within 72 hours after delivery. Results: Prevalence of periodontal disease was $41 \%$ (54/132). Cases showed a significantly higher proportion of bleeding $(86.7 \%$ vs. $68 \%, \mathrm{p}=0.026)$ and a greater maximum periodontal pocket depth on probing $(3.9+1.6$ vs. $3.2+1 \mathrm{~mm}, \mathrm{p}=0.043)$. No differences in previous periodontal disease, attachment loss, and the percentage of periodontal disease were detected between study groups. Logistic regression $1.28-13.69, \mathrm{p}=0.018)$ and the periodontal pocket depth $(5.14 ; 95 \%$ CI: $1.50-17.6, \mathrm{p}=0.009)$. A trend towards less risk of preterm birth associated with periodontal disease as gestational age increased was observed. In addition, the population attributable risk was $16 \%$, and higher with decreasing gestational age. Conclusions: In this population only bleeding index and periodontal pocket depth were risk factors for preterm birth in pregnant women, and the risk rose with the increase in prematurity.
Introduction: Periodontal disease, as a source of subclinical and persistent infection, may induce revealed that preterm birth was associated with the bleeding index (adjusted odds ratio 4.19; $95 \% \mathrm{CI}$ 


\section{7}

POSTNATAL GROWTH AS A PREDICTOR OF RETINOPATHY OF PREMATURITY: A MULTIVARIATE MODEL

Nieto R, Benítez A, Dinerstein A, Pérez G, Solana C. Maternidad Ramón Sardá. Argentina.

Introduction: Recent studies suggest that postnatal growth and related factors such as IGF levels can play an important role in the development of retinopathy of prematurity (ROP). Objective: To evaluate clinical and nutritional factors associated with the development of ROP. Methods: Cohort study. Inclusion criteria: infants born between 08/2003 and 11/2005 with gestational age (GA) $<32$ weeks and birth weight $(\mathrm{BW})<1500 \mathrm{~g}$ at birth. Daily growth in grams was recorded from day of BW recovery up to day 28 . Statistical analysis: A predictive logistical regression model was constructed Results: 152 patients met the inclusion criteria, 8 were transferred and 3 died before day 28 .Data from the remaining 141 patients were analyzed. The fifty five patients who developed ROP $(39 \%)$ had lower GA: $28.3 \mathrm{w}$ vs. $29.6 \mathrm{w}(\mathrm{p}<0.001)$, lower BW: $1090 \mathrm{~g}$ vs. $1190 \mathrm{~g}(\mathrm{p}=0.007)$ and higher prevalence of late onset sepsis: $44 \%$ vs. $22 \%$ ( $\mathrm{p}=0.012)$, more oxygen days: 55 vs. $28(\mathrm{p}<0.001)$, more days in mechanical ventilation: 21 vs. $10(\mathrm{p}=0.02)$, and higher incidence of bronchopulmonary dysplasia: $51 \%$ vs. $31 \%(\mathrm{p}=0.02)$, higher caloric and protein deficit: $-695 \mathrm{cal} / \mathrm{k}$ and $-22 \mathrm{~g} / \mathrm{k}$ vs. $-466 \mathrm{~g} / \mathrm{k}$ and $-15 \mathrm{~g} / \mathrm{k}(\mathrm{p}=0.003$ and 0.004 respectively), and had lower daily growth: $6 \mathrm{~g} / \mathrm{k} / \mathrm{d}$ vs. $22 \mathrm{~g} / \mathrm{k} / \mathrm{d}$ $(\mathrm{p}=0.038)$. Multivariate analysis showed that for each week of GA the chance of ROP decreased $40 \%$ (95\% CI 19-45). When postnatal growth was analyzed, patients whose growth was in the 3rd and 4th quartile had 68\% (95\% CI 2-89) and 86\% (95\%CI 15-94) less chance of ROP when compared with the infants of the lower quartile. Conclusions: GA and postnatal growth failure can be associated independently with ROP development. The impact of new nutritional interventions for decreasing postnatal growth restriction should be evaluated. This paper confirms the relevance of GA as a major guide for ROP screening in our clinical setting.

\section{8}

\section{CHILD MORTALITY IN THE NORTHEAST REGION OF BRAZIL}

Cardoso V, Ribeiro V, Barbieri M, Santos A, Bettiol H, Silva A. Post Graduation in Collective Health, Universidade Federal do Maranhão, São Luís, Maranhão, Brazil. University of São Paulo, Ribeirao Preto. Brasil.

Objectives: To describe and analyze infant mortality using environmental, socioeconomic and biological indicators in six cities in the Northeastern region of Brazil. Methods: A case-control study was conducted between January and December of 2007 of 218 cases and 432 controls. Cases were identified on the Ministry of Health Mortality Information System and in hospitals where the death occurred. Research of medical records was done alongside interviews with the mothers to clarify the basic cause and study the related variables. Controls were paired by age and socioeconomic level. Deaths were classified following criteria of avoidability in the ambit of the Public Health System (SUS). Univariate and multivariate analyses were done. Relative frequency odds ratio, confidence interval and p-value were calculated. Results: The majority of the deaths were in the early prenatal period $(56.9 \%$ on day 1 and $97.4 \%$ by day 4$)$. Univariate analysis observed a significant association $(\mathrm{p}<0.05)$ when the mother was family head (OR 3.9), was under 18 years old (OR 2.3) and had less than 8 years of schooling (OR 1.9); without prenatal care (OR 10.6), history of a problem during the pregnancy (OR 1.97); history of a problem at birth (OR 12.9), Apgar Index < 7 (OR 3.8) low birth weight (OR 11.8), preterm (OR 9.8), congenital malformation (OR 21). Mothers who did not work outside of the home were a protective factor (OR 0.5 ). In the multivariable analyses low birth weight (OR 5.8) and history of a problem at birth (OR 4.7) remained associated. The most frequent causes of deaths were perinatal (32\%), infectious diseases (17\%) and malformations/deformities (12\%). It was observed that the deaths were avoidable with adequate care of the mother during pregnancy $(55 \%)$, through adequate diagnosis and treatment $(15 \%)$ or actions taken to promote health $(10 \%)$. Conclusion: Occurrence of deaths which were potentially avoidable reflects a deficiency in the quality of care for pregnant women, as well as for newborns at birth and when they begin to access health services.

\section{0}

EFFECTS OF WEIGHT AND LENGTH AT BIRTH ON THE HEIGHT OF SCHOOLCHILDREN AND YOUNG ADULTS IN A BRAZILIAN SETTING

Cardoso V, Ribeiro A, Mesquita D, Barbieri M, Bettiol H. Faculdade de Medicina de Ribeirão Preto, São Paulo (FMRP-USP). Brasil.

Introduction: Impaired intrauterine growth favor lower heights in adults. Objectives: To assess the associations of birth weight and length with height at school age and with final height of participants of the 1978/79 birth cohort in Ribeirão Preto, Brazil, controlled by biological and social characteristics during these ages. Methods: Data of 1147 individuals at birth, school age and adult age ( $23 / 25$ years) were obtained. The variables studied were collected at birth (weight, length, sex, maternal schooling and smoking habit, birth order, maternal age and marital status, occupation of the family head), a school age (height-for-age z-score and type of school) and adulthood (skin color, final schooling, and age at menarche for women). Results: Linear regression analysis was performed in separate models for weight and height. In non-adjusted analysis, children with higher birth weight and length, born to mothers with better schooling, first born, born to non-manual workers and studying in private schools showed higher height at school age for both genders; smoker mothers and with a companion were associated with lower height among girls. After adjustment, weight and height, maternal age and birth order continued to be associated in both genders, family head occupation continued to be associated among boys and maternal marital situation among girls. In adults, higher birth weight and height, mothers with higher schooling, being a first born, older mothers, skilled occupation of the family head, studying in private school, higher height at school age and higher final schooling, and late menarche in women were associated to higher height in both genders. After adjustment, birth weight and length, schoolchild's height and age at menarche for women were associated to higher height in both genders. Conclusion: The effect of birth weight and length persisted on schoolchildren's and young adults' height even after adjustment, but the effect of the remaining variables on schoolchildren's heigh disappeared in adult age after adjustment for schoolchildren's height. The height at school age seem to incorporate the effects of factors present in previous phases of life on the growth profile during this initial period, thus becoming an important predictor of adult's growth.

\section{9}

\section{FOOD REFUSAL IN CHILDREN UNDER AGE THREE YEARS}

Bravard C, Franco D, Sánchez Bernal S. Universidad Nacional de Asunción. Paraguay.

Introduction: The preferences and refusal to food are influenced by learning in early life. Rejection is a reaction of opposition to the food itself or the circumstances. Detection of rejection creates the challenge of preventing it to achieve normal growth and development of children. Objective: To determine the influence of food refusal in the nutritional status of children 4 to 36 months of age attending the Social Security Institute (IPS by its initials in Spanish) and a private practice in Asuncion. Subjects and Methods: The subjects studied were 31 children with food refusal (CWFR) and 28 without (CWOFR). A survey was conducted to mothers in order to perform an observational and analytical cross-sectional pilot study with cohort sampling. Results: Median age was 18.1 months (Range: $4.9-36$ months). Of the CWFR, 58\% $(\mathrm{n}=18)$ had an exclusive maternal breastfeeding duration of less than 6 months, which was not significant compared to other members of the population $\left(\chi^{2}\right.$ $\mathrm{p}=0,3)$. Of the CWFR, $48 \%(\mathrm{n}=15)$ started rejecting food in the first semester of life. In both practices, $74 \%(n=23)$ of CWFR were fed in a different time (before) other members of the family, while $54 \%$ $(n=15)$ of CWOFR were fed with the family. Some $48 \%$ of CWFR played while they ate. According to the $\mathrm{z}$ scores, $86 \%(\mathrm{n}=51)$ of the children were well nourished for of weight/age (W/A) and $80 \%$ $(n=47)$ for length/age (L/A), while malnutrition caused by excesses was seen in $44 \%(n=22)$ according to the W/A in both groups. No significant association was found regarding the nutritional status measured by the $\mathrm{Z}$ score in W/A, L/A or weight-length (W/L) in children with food refusal respect to those without it $\left(\chi^{2}\right.$ Fisher $\left.\mathrm{p}=0,41 ; \mathrm{p}=0,84 ; \mathrm{p}=0,54\right)$. Conclusion: The beginning of refusal was more frequent in the first semester of life. There was not association between food refusal and deficient nutritional status.

\section{1}

A SIMPLE METHOD FOR MAINTAINING CONTINUOUS POSITIVE AIRWAY PRESSURE (CPAP) IN PRETERM INFANTS IN LOW-INCOME COUNTRIES

Tejerina H, Díaz M, Irigoyen M, Soliz A, Claure N. Hospital De La Mujer La Paz Bolivia. Miami Children's Hospital, Babies without Borders, Miami Florida, USA. Neonatology/Pediatrics, University of Miami Miller School of Medicine, Miami, Florida, USA. Hospital de la Mujer La Paz Bolivia Bolivia.

Background: Nasal continuous positive airway pressure (nCPAP) is effective in preterm infants with respiratory insufficiency and is commonly used in newborn care centers in poor countries due to its relatively low cost. In many of these centers compressed air is not always available and in some cases nCPAP is given with $100 \% \mathrm{O} 2$. In these centers nCPAP drivers can be a suitable and inexpensive alternative for generating nCPAP with room air. Objective: To compare the efficacy of a simple method of delivering nCPAP to maintain ventilation and gas exchange in a group of preterm infants compared to conventional nCPAP. Methods: Preterm infants admitted to the NICU of the Hospital de la Mujer in La Paz, Bolivia who required nCPAP were studied during 4 hours of conventional and 4 hours of simple nCPAP in random sequence. Simple nCPAP was generated with a CPAP flow driver device (Orion, Viasys Healthcare). Conventional nCPAP was delivered with a conventional ventilator (Sechrist Industries). Results: Sixteen infants (BW 1623 $\pm 409 \mathrm{grams}$, GA $31 \pm 4$ weeks, age 0 to 10 day) were enrolled. The conventional CPAP pressure was from 4 to $6 \mathrm{cmH} 2 \mathrm{O}$. The level of simple nCPAP was 5. Abdominal circumference, body temperature, arterial oxygen saturation, respiratory rate, cardiac rate, fraction of inspired oxygen, $\mathrm{pH}$, and $\mathrm{CO} 2$ tensions did not differ between nCPAP methods. Data in mean SD or median (25th-75th percentile). Conclusion: Preliminary data indicate the simple nCPAP method is comparable to conventional nCPAP delivery methods. This method may become a suitable alternative for the care of infants in resource-limited country. 


\section{Author Index to Abstracts}

(Numbers cited refer to page numbers)

\author{
Abraham S, 446 \\ Aranda C, 447 \\ Araya M, 447, 449 \\ Araya S, 447 \\ Arbo A, 447 \\ Arredondo M, 449 \\ Astudillo F, 446 \\ Ayala M, 447 \\ Bagés C, 446 \\ Bagés MC, 448 \\ Balboa P, 448 \\ Barbieri M, 449 \\ Benítez A, 449 \\ Bettiol H, 449 \\ Bravard C, 449 \\ Buongermini A, 447 \\ Burrows R, 448 \\ Cai W, 448 \\ Cardoso V, 449 \\ Castillo M, 448 \\ Castillo-Durán C, 446, 448 \\ Chiolo MJ, 447 \\ Cisternas F, 449 \\ Claure N, 449 \\ Cutri A, 447 \\ Delgado V, 447 \\ Delva J, 448 \\ Díaz M, 449 \\ Dinerstein A, 449 \\ Di Pietro S, 446 \\ Espinoza A, 446, 448 \\ Fernández V, 446 \\ Ferrero F, 447 \\ Figueroa G, 446 \\ Flores S, 446 \\ Franco D, 449 \\ Gaitán D, 446 \\ Gerez G, 446 \\ Gómez M, 446 \\ González M, 449 \\ Gotteland M, 446 \\ Grandi C, 448 \\ Grandi G, 447 \\ Guendelman M, 448 \\ Hevia M, 448 \\ Irigoyen M, 449 \\ Leonardelli A, 447 \\ Le Roy C, 446, 448
}

López de Romaña D, 447

Lovera D, 447

Medina M, 447

Mena C, 447

Méndez M, 449

Mericq V, 448

Meritano J, 446, 448

Mesquita D, 449

Miranda C, 446

Nieto R, 449

Núñez H, 447, 449

Olivares M, 446, 447, 449

Ossorio MF, 447

Pavez L, 449

Peirano P, 448

Pérez G, 449

Pérez H, 447

Piccardo Van de Perre C, 448

Pizarro F, 446, 447, 449

Ribeiro A, 449

Ribeiro V, 449

Rivas P, 446

Rosas L, 448

Ruz M, 447
Sanabria G, 447

Sánchez Bernal S, 449

Santos A, 449

Santos J, 448

Schilling W, 448

Sierralta W, 449

Silva A, 449

Solana C, 449

Soliz A, 449

Soria R, 447

Speisky H, 446

Tejerina H, 449

Teran C, 447

Torrejón C, 448

Torres F, 447

Troncoso M, 446

Trungadi M, 448

Ureta E, 448

Uribarri J, 448

Valencia A, 447

Valenzuela X, 448

Vega N, 446

Vlassara H, 448

Weisstaub G, 448 